\title{
IS THE MANDATORY IMPLEMENTATION OF WORKPLACE HEALTH MANAGEMENT SYSTEMS HARMFUL TO THE COMPETITIVENESS OF EUROPEAN EMPLOYERS OR AN OBSTACLE TO ECONOMIC GROWTH?
}

\section{Schiller, T.}

Thomas Schiller / University of Economics, Prague, Faculty of Business Administration, W. Churchill Sq. 4, 13067 Praha 3, Czech Republic.Email:Thomas.Schiller@gmx.de

\begin{abstract}
This paper analyses, reviews and connects the existing literature about workplace health management systems. We investigate the empirical evidence if a mandatory implementation could lead to a Pareto improvement for all stakeholders. This evaluation is based on the inclusion of several studies, which are not yet connected to the health-related issue. The increasing incidence of employee health issues generates high costs for employers as well as for insurers. Workplace Health Management Systems act as preventive measures in reducing health-related costs. Many case studies are used to explain the concepts and the specific cost reduction for the companies analyzed. But there is still a lack of a broad empirical base to provide convincing evidence for the costeffectiveness of these programs. To demonstrate the general efficiency of these systems, several studies of different concepts with similar characteristics are compared to ensure, that the mandatory implementation leads to positive effects on the economy. We find that by implementing just a few prevention measures, positive returns can be achieved for a majority of sectors. Given that the market seems incapable of creating this allocation improvement by itself, the integration of health management into the Working Conditions Act seems reasonable, since this could allow a Pareto-efficient outcome to be achieved. Consequently, implementation will not lead to a reduction in the competitiveness of European employers, but rather to increased staff retention and improved productivity due to fewer employee sick days and an improvement in public health and makes the mandatory implementation of workplace health management systems a considerable issue for policymakers.
\end{abstract}

Keywords: firm employment conditions, government policy and regulation, firm employment decisions

JEL Classification: M14, M48, M51 


\section{Introduction}

The health of employees plays an ever-increasing role in companies. "After the growth spurts induced by automation and information technology, a potent growth factor is now mental health and competence - the system of the human being as a whole" (Buchenau, 2018). But to what extent is this the responsibility of the employer?

Some political actors see the benefits of Integrated Workplace Health Management (IWHM) as a necessary tool for an improvement in public health. The Commission of the European Parliament has reported in its EU Strategic Framework on Health and Safety at Work 20142020that very few companies pursue an IWHM system, that action is needed urgently, and that in most countries legal regulations on safety at work are not complied with (European Commission, 2014). Therefore, mandatory implementation of Workplace Health Management Systems could assist in improving the implementation rate and consequently economic growth. But when considering mandatory implementation, it is necessary to carefully evaluate the given evidence of the efficiency of these programs to prevent a harmful setback for employers and economic damage being caused. Furthermore, it is important to identify the existence of a market failure to justify public intervention.

Globalization and demographic changes have resulted in strong competition between employers for highly competent employees, not only on a national level but also on a supranational and international level (Buchenau, 2018). Recruiting costs or costs for the integration of new employees arise with every employee change or long absence due to illness. Therefore, companies need to take staff retention measures in order to retain the highest performing employees and also need to minimize preventable time lost due to sickness. Certainly, remuneration is an important factor for an employee, when it comes to a choice between different employers. However, recent studies (Hoffmann, 2018) have found that salary is not the most important factor in the context of employee job satisfaction, but that factors such as work-life balance and health awareness are of special significance. Additional services, such as integrated workplace health management systems (IWHM), have become a focal point for employees.

Demographic developments indicate that subsequent generations of employees will have to work more years than the current one. In 2024, the group comprising 50-65-year-olds will constitute $40 \%$ of the labour force (Thiehoff, 1999). Mental health issues have increased in performance-oriented societies and are the second most frequent reason for incapacity to work after musculoskeletal disorders. In order to counter this trend, prevention measures in the workplace and a functioning health management system become increasingly important. Figure 1 shows that in a time span of 20 years, the number of days of absence has more than tripled and the number of incidents has increased similarly.

Not only is the topic relevant to staff retention or limiting public health deterioration, but it has the potential to be a competitive advantage and to generate significant revenue growth through higher cost-effectiveness. This applies to employers as well as to insurers because the expenses for a functioning IWHM system are lower than the cost savings arising from lower rates of absence or from reduced use of medical services and medicines. In a current survey by the University of Bayreuth, Germany, $76 \%$ of employee sick days relating to chronic illness can be avoided through prevention measures (Thiehoff, 1999). The German 
Federal Institute for Occupational Safety and Health expects that 35\% of work incapacity can be prevented by employer IWHM measures (Thiehoff, 1999).

Figure 1 | Absence and Incidents per 100 Workers

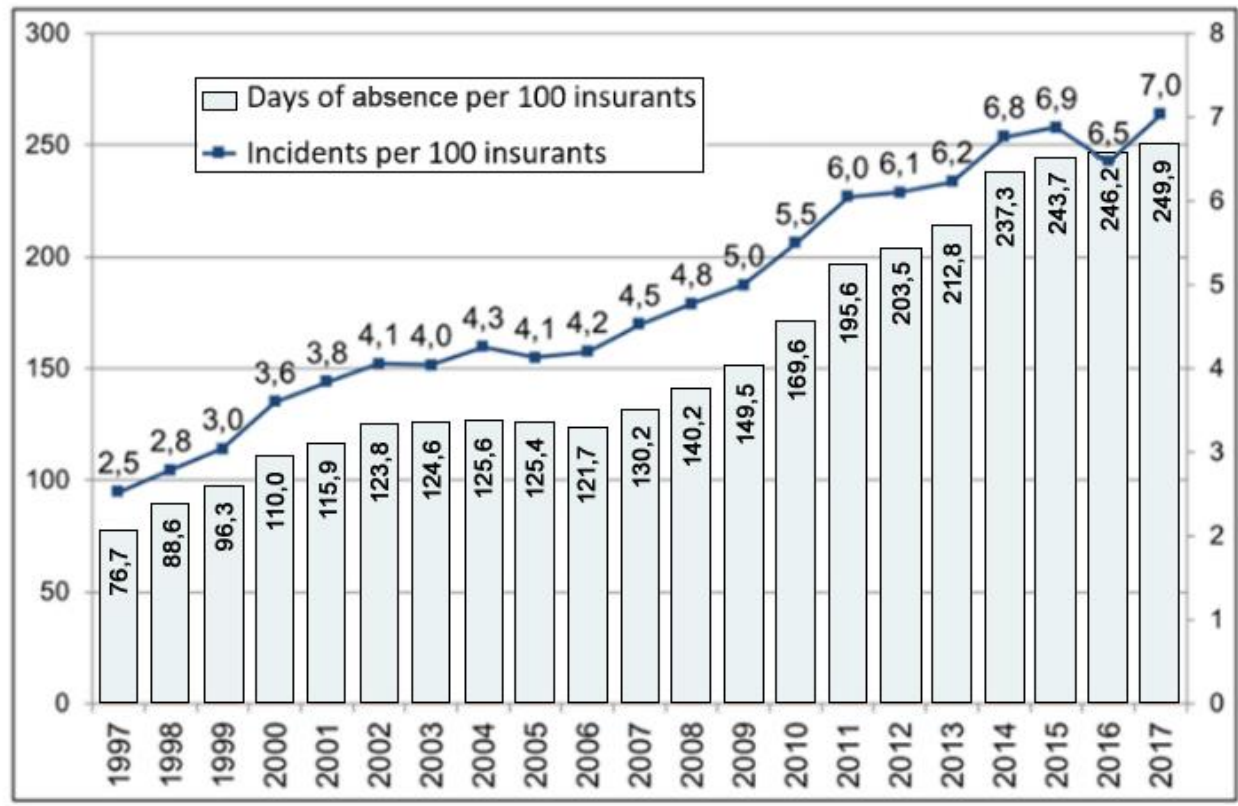

Source: Marschall et al. (2018).

The employee as a third stakeholder in the IWHM system, besides the employer and the insurer, also benefits from improved mental and physical health, but also from lower insurance premiums in the long run (Ryan et al., 2018). There seems to be a breakdown in the market since the IWHM system would make all three direct stakeholders better off, yet it has not been broadly implemented. This situation suggests that a statutory regulation constitutes a Pareto improvement.

In this paper, the existing literature on different forms of IWHM is closely analyzed in terms of its effects on different operational variables. Our approach is unique in that we do not concentrate on the literature on one narrow definition of IWHM, which is mostly countryspecific, but instead, we consider many forms and evaluate the advantages and shortcomings. Therefore, we introduce at first the concept of the German BGM to provide an example for such an approach, then we analyse, compare and review the existing literature about the efficiency of the BGM in Germany and other internationally applied workplace health management systems. Further, we discuss the similarities of the American concept of the workplace wellness programs to the German BGM. Since these programs have common functionality, we include the results of the related efficiency studies of the WWP in this evaluation. Based on this analysis, we have a wide range of empirical studies, which points out the efficiency of these programs. Furthermore, we identify an existing market failure which harms economic growth. Afterwards, the advantages and disadvantages of implementation are assessed by estimating possible cost savings in order 
to evaluate whether a statutory regulation, for example in the Working Conditions Act of each country, is a possible solution to this market failure.

\section{The Concept of the German BGM as Example of an Integrated Workplace Health Management System}

At first, it makes sense to define the concept of the German "Betriebliches Gesundheitsmanagement" (BGM) to give an understanding of its characteristics because it includes many, but not all, aspects of "integrated workplace health management" known in the UK and Australia. For example, it encompasses workplace health promotion, workplace health prevention and workplace health education. It also covers workplace safety, but since workplace safety is part of existing mandatory legislation in Germany (ArbSchG), it is not included in the definition of this paper. For reasons of simplicity, we refer to the BGM as an integrated workplace health management program (IWHM). The IWHM addresses all health-related issues of the employees of a company, which includes not only the sick but also the healthy employees. It uses operating numbers to analyze and monitor the given health status of the workforce and design measurements to improve the corporate health level. The instruments used comprise sports courses, subsidies for certain sports activities, encouragement to follow healthy food diets, monitoring of staff turnover rates and of sick days, as well as the leadership attitudes of the managers in the company (Junker \& Kaluza, 2017). In the case of illness, it also includes measures to ensure a quick recovery and an efficient return to work. The objective is to improve the long-term health of all employees by using nudging techniques and giving financial incentives to promote prevention and health.

Figure 2 | Fully Integrated BGM Concept

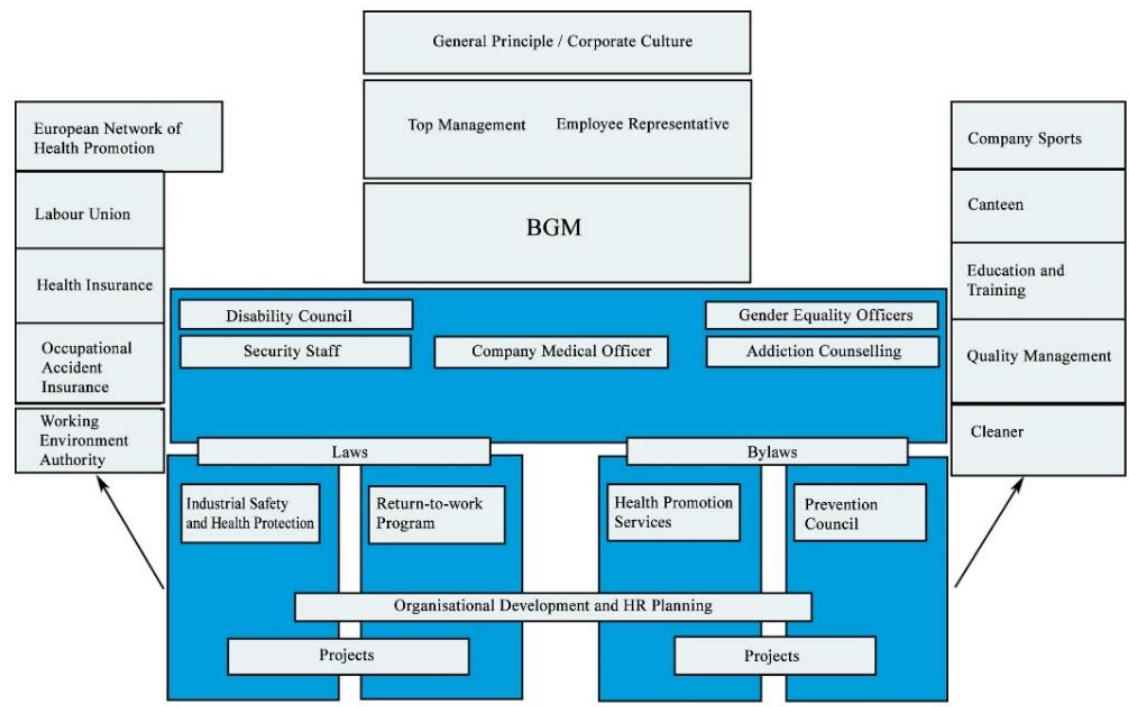

Source: Singer \& Neumann (2010). 
Figure 2 (Singer \& Neumann, 2010) provides a model of an extensively developed and complete IWHM program in the context of a German corporate structure for a company with more than 200 employees. Since the structure of a company of this size depends on the national legislation on the integration of labour unions etc., the German company structure is used as an example of the possible implementation of an IWHM program. The IWHM program acts as the corporate unit responsible for all parts in the blue area in Figure 2. Furthermore, it influences the top management of the company and thus the corporate culture (Huber, 2010). Due to the central position of the BGM, it is able to encourage cooperation between the single units and generate synergies (Kern, 2018) because it simplifies communication.

For the implementation process, seven aspects have to be considered according to (Kern, 2018). At first, health-related strategies have to be designed by the company's strategic management office. The incentive system for the leaders and managers depends, among other indicators, on the health status of the workforce. Corporate coaches for social and health services have to accompany each change process within the company. Offers for sports activities, food or other health-related topics have to be organized according to the needs and demands of the workforce. Moreover, cooperation can be established between particular groups of the health sector and the company. Finally, all health management measures have to be evaluated in accordance with the company's goals (Kern, 2018). After the implementation of the BGM, a regular evaluation process must be established to monitor compliance and analyze key indicators.

Figure 3 | Indicators for the Evaluation of the BGM

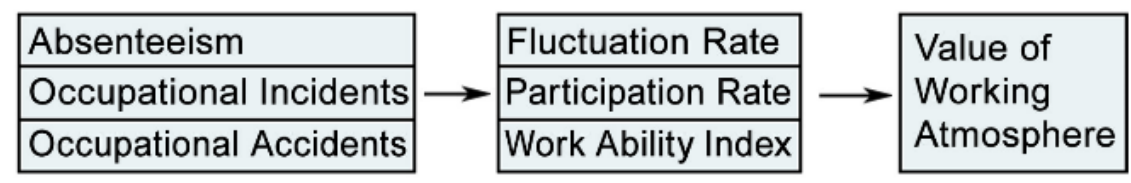

Source: Buchenau (2018).

Since the main costs for employers are incurred due to employees' sick days, the absence is the first issue. The first column in Figure 3 shows those issues which directly generate costs for the employers. The second column comprises indicators which are indirectly related to the costs. The turnover rate increases the costs of education and training. The participation rate in such measures decreases costs as it results in a lower average number of sick days.

A recent evaluation plan for a well-implemented IWHM is the PDCA Cycle, illustrated in Figure 4 (Scholz et al., 2018). It splits the procedure into four parts. The first part is the planning phase which analyzes the given demand using quantitative and qualitative measures - the financial budgets are evaluated, and specific goals are set up. The second step is the implementation of the plan of action. The third step is collecting and evaluating data about the implementation. The last step is to make adjustments to the actions, measures and goals. On-going re-evaluation is highly important in order to ensure that the established BGM remains efficient. 


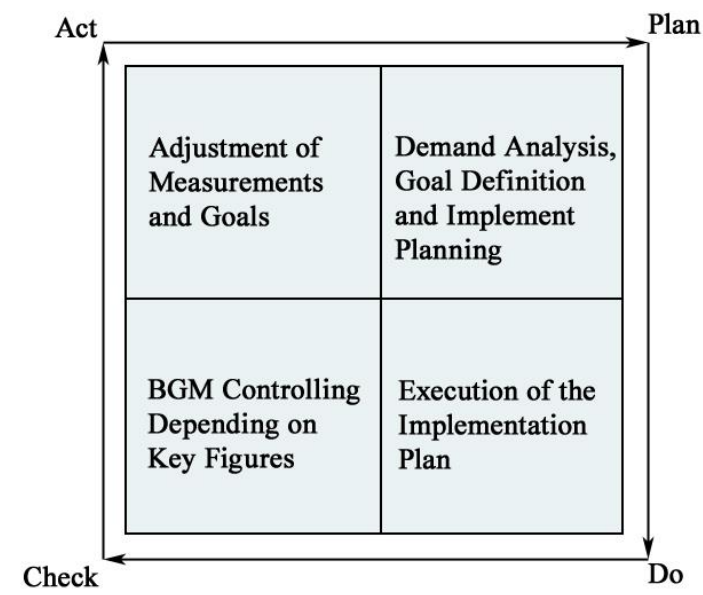

Source: Buchenau (2018).

All three affected stakeholders (employers, employees and health insurers) benefit from the establishment of a BGM. The company profits from reduced costs due to fewer employee sick days, fewer work accidents, a better corporate image, higher satisfaction among the workforce, improved communication and cooperation between the units within the company, higher productivity, better production quality, lower staff turnover and the saving of resources. These benefits are not only theoretical considerations but also the result of a survey of 1451 European companies in 2008. (Kruse \& Wittberg, 2008) In addition to an improvement in their health, employees benefit from a lower stress level, reduced costs for leisure activities and own health care, healthier working conditions, higher staff retention, higher motivation and a better working atmosphere. Health insurers cover the largest part of the expenses if employees use health services and buy medicine. By decreasing illness rates, the insurers significantly reduce their costs. Hence, the concept of the IWHM (BGM) presented serves to support all three stakeholders by regular monitoring of employees' health status, providing preventive and educational measures and offering the employees financial incentives. These are in addition to the employees' intrinsic motivation to remain healthy.

\section{Review of Empirical Evidence for the Effectiveness of Workplace Health Management Programs}

This chapter discusses the results of several papers evaluating the workplace health management programs of different companies. One of the key issues when evaluating workplace health management programs is that they are always company-specific and address very particular characteristics. Therefore, it is difficult to develop general findings and derive policy implications which can be applied across industries. Furthermore, there are not many empirical studies on the topic of the German BGM, which can be evaluated and transferred into a general recommendation. International health-oriented programs 
have therefore also been taken into account since they provide insights across sectors and countries. At last, we include studies about the American workplace wellness programs in the analysis and comparison to ensure a sufficient base to evaluate if the effects can be generally applied.

Although several case studies such as (Ryan et al., 2018), have demonstrated the cost efficiency of establishing workplace health management programs (WHMP) in Germany similar to the German BGM, many companies do not implement such a program. This shows that in practice there is an information asymmetry between employers and employees as to their preferences. While the employees appreciate such measures in particular in the context of staff retention, the employers are partly not informed about their employees' preferences and, the effectiveness of the measures, and they have doubts about whether these programs are applicable to their companies and about the additional expenses.

A major issue for general implementation is that employers are not informed about the benefits. Therefore, it is necessary to demonstrate to the employers the high return on investment resulting from these programs. This issue is also addressed by a study (Ryan et al., 2018) which focuses on the WHMP in an Australian hospital. The aim of the program is to improve the employees' awareness of-of their own and their colleagues' health. It includes training to recognize symptoms of ill health and injuries and to report them before they become serious. This improves relationships among the employees and helps them to manage daily stress by assisting one another, in particular in cases of previous ill health. The program consists of a daily six-minute group exercise which is used for health education, relaxation, physical activity, leisure conversation, and social integration. After the launch of the program, the insurance companies monitored indicators which give insights into the duration of the employees' average number of sick days and the time lost due to injuries. The study finds that if the workforce acts more in accordance with health selfmanagement, these two indicators decrease. Furthermore, the indicators can be used to measure cost-effectiveness and productivity increases. The results of this study indicate a decrease in the number of incidents (from 119-88 claims), fewer working hours lost due to sick days and a decrease in the cumulative costs of injuries. The result is calculated by analyzing the levels in the three years prior to the implementation of the program and comparing them with the levels in the three years after the implementation. From the perspective of the insurers, the claims paid for wages, and medical treatment decreased from $\$ 350.000$ in the year prior to the launch of the program to $\$ 150.000$ in the year after. (Ryan et al., 2018) This study does not investigate the implementation of a completely integrated workplace health management program, but rather a program with one single aspect of this. This program already has a positive effect on employees' health. Whilst this demonstrates the power of the program, the results have to be interpreted carefully, since a hospital in Australia may face different issues too, for example, a car factory or a school. Differences can also exist among countries.

The study (Bulotaite et al., 2017) based on multiple questionnaires investigates if the given workplace health promotion of health care employees in three northern European countries leads to a willingness to change their lifestyle compared to partially given workplace health management systems. The results for the countries varied strongly. The number of health 
care employees who were willing to change their lifestyle for better personal health ranged between 3\% and 27\%. (Bulotaite et al., 2017) The study used internationally self-collected survey answers combined with a cross-sectional data set. Although the results show a correlation, the effects cannot be interpreted as causal. In particular, an issue of endogeneity arises, because the reports are about the given health-related infrastructure and the expectations/feelings are from the same group of individuals.

The authors of (Cullen et al., 2018) conducted a systematic review study to create a more general perspective on the effect of workplace health interventions. This study focuses on the return-to-work (RTW) programs and also includes work disability management (MD). It evaluates 36 studies which use different methods such as randomized trials, nonrandomized trials and cohort studies with historical and concurrent comparisons. All studies focus on health, service coordination or work modifications. Some of the studies use multidomain approaches which address more than one aspect of IWHM. The authors point out that only 12 out of 36 studies could be used for interpretation since the others were insufficient because of unreliable results or incomparability of the relevant variables. The 12 remaining studies are grouped according to their focus and interventions. The review study (Cullen et al., 2018) furthermore ranks the different interventions of the studies depending on their strength, as presented in the following table.

Table 1 | Overview of Studies Evaluating Applied Intervention and Outcomes

\begin{tabular}{|c|c|c|}
\hline Levels of evidence & Intervention (No. of $\mathrm{H}$ and $\mathrm{M}$ studies) & Outcome \\
\hline \multirow{3}{*}{ Strong (positive) } & Multi-domain MSK interventions (4H, 10M) & Lost time \\
\hline & Work-focused CBT for MH conditions $(6 \mathrm{H}, 1 \mathrm{M})$ & Lost time \\
\hline & Work-focused CBT forMH conditions $(4 \mathrm{H})$ & Cost \\
\hline Strong (no effect) & CBT for $\mathrm{MH}$ conditions $(6 \mathrm{H}, 1 \mathrm{M})$ & Lost time \\
\hline \multirow{5}{*}{ Moderate (positive) } & Graded activity $(2 \mathrm{H}, 1 \mathrm{M})$ & Lost time \\
\hline & Work accommodations $(2 \mathrm{H}, 3 \mathrm{M})$ & Lost time \\
\hline & Multi-domain MSK interventions $(1 \mathrm{H}, 2 \mathrm{M})$ & Work functioning \\
\hline & Work-focused CBT for $\mathrm{MH}$ conditions $(2 \mathrm{H})$ & Work functioning \\
\hline & Multi-domain MSK interventions $(2 \mathrm{H}, 4 \mathrm{M})$ & Cost \\
\hline \multirow{2}{*}{ Limited (positive) } & Work accommodations $(1 \mathrm{H}, 1 \mathrm{M})$ & Cost \\
\hline & Health-focused multi-component $(1 \mathrm{H})$ & Work functioning \\
\hline \multirow{4}{*}{ Limited (no effect) } & Work hardening $(1 \mathrm{H})$ & Work functioning \\
\hline & Physician training $(1 \mathrm{H})$ & Lost time \\
\hline & RTW plan $(1 \mathrm{H}, 1 \mathrm{M})$ & Lost time \\
\hline & RTW plan $(1 \mathrm{H})$ & Cost \\
\hline \multirow{4}{*}{ Mixed } & Work hardening $(1 \mathrm{H}, 1 \mathrm{M})$ & Lost time \\
\hline & Health-focused multi-component $(3 \mathrm{H}, 2 \mathrm{M})$ & Lost time \\
\hline & Graded activity $(1 \mathrm{H}, 1 \mathrm{M})$ & Cost \\
\hline & Health-focused multi-component $(2 \mathrm{H})$ & Cost \\
\hline \multirow{5}{*}{ Insufficient } & Case management $(1 \mathrm{M})$ & Lost time \\
\hline & Work accommodations (1M) & Work functioning \\
\hline & Worker education/training $(1 \mathrm{M})$ & Cost \\
\hline & Supervisor education/training $(1 \mathrm{M})$ & Cost \\
\hline & Work hardening $(1 \mathrm{M})$ & Cost \\
\hline
\end{tabular}

Source: Cullen et al. (2018). 
$\mathrm{H}$ and $\mathrm{M}$ stand for high-quality study and medium quality study, which were differentiated depending on their number of observations, their timeframe for follow-up studies and study design, as well as nine other criteria. The third column shows the outcome variable of interest. The identified results show that traditional cognitive behavioural therapy (CBT) programs do not have an impact on the reduction of time lost due to illness or mental health issues. Instead, CBT programs related to work solutions have positive effects on the RTW and MD. This implies that cognitive behavioural therapy addressing work-related issues at work leads to a decrease in lost time and therefore a reduction in the costs. The strength of the model increased enormously when a multi-domain approach was applied. A multidomain approach consists of a minimum of two components, such as service coordination and work modification or health approaches. The health of the employees increased in particular where mental health issues, musculoskeletal injuries and pain-related cases were concerned. This led to a strong decrease in sick days and in financial costs for the employers. These results remain coherent for the given set of studies which include seven countries. The ranking results show the effectiveness of each intervention with regard to the investigated outcome. These ranking results must be interpreted carefully since the efficiency of the interventions depends on the company's specific needs.

Although the studies concerning the German BGM and the international workplace health management program provide broader evidence across countries and industrial sectors, the existing results are not sufficient to ensure that mandatory implementation can be justified. Since the Pareto-efficient characteristics are not reliable enough, it is necessary also to include studies of "effective workplace wellness programs" (WWP) from the US in this evaluation It is fitting to include studies about the WWP because many IWHM measures are also included in the WWP. In the US, WWPS are often presented as employer services, but in fact, contribute to the company's productivity. WWPs address outcomes such as greater productivity, lower costs for health care, and higher workforce morale. In the best case, they comprise the following six pillars: multilevel leadership, alignment, accessibility, partnership, communication and scope, and relevance and quality (Berry et al., 2010). These programs were set up because the health insurance system in the US is employment-based and health insurers can renegotiate insurance contributions. This system creates a higher incentive for employers to promote the health of their employees since these aspects enhance the results of the company. Therefore, studies about the WWP are well designed for comparison with those on the IWHM. The major difference is the origin and original goal of these programs. Whereas in the US WWPs are initiated by companies with the purpose of cost reduction by a decrease in contributions to health insurances and for staff retention, the IWHM programs are mainly offered by public health insurers to companies and are accompanied by side benefits such as staff retention. In the case of WWPs, the return on investment ratio of these programs has been evaluated in many studies (Berry et al., 2010), their results range from 2.71:1 to 6:1 (Berry et al., 2010), including many industrial sectors such as hospitality, tourism, energy communication, grocery retail, software, education, finance, manufacturing, and health care (Berry et al., 2010). This wide range of industries shows that interventions in the workplace addressing the physical and psychological health of the employees is profitable for the employer. 
The evaluation of workplace wellness programs has received more public attention in the US compared to Europe, and consequently, more literature has been published. Based on a systematic review of more than a 100 peer-reviewed studies, the study (Baicker et al. 2010) argues that for every $\$ 1$ spent on wellness programs the company receives $\$ 3.27$ due to the fall in medical costs and another reduction of $\$ 2.73$ in costs due to absence (Baicker et al., 2010). Although in the case of Germany and most of the EU countries these benefits are split between health insurers and companies, the ROI is still above 100, and a step-by-step implementation does not involve large entrance costs (Bulotaitè et al., 2017).

The existing quantitative studies on the BGM in Germany are not enough to clearly indicate a profitable outcome for companies from a general perspective because there is not enough literature to cover several industrial sectors. By including the international healthoriented programs, the evidence increases across countries still remain questionable, because these programs are directly connected to single measures for certain healthrelated issues and therefore very specific. By including the literature and studies about the cost-effectiveness of the American workplace wellness programs, reliable predictions about the benefits of the IWHM programs for all three stakeholders can be made as long as they can be applied in similar settings in the EU as in the US. Hence, it is possible to draw policy implications from the economic benefits of workplace health management.

\section{Policy Implications based on Economic Benefits from IWHM in the EU}

Cost-effective illness prevention in the workplace has also been discussed by policymakers in the EU who have published a strategic framework on health and safety at work 20142020 (European Commission, 2014). European policymakers started working on the subject of occupational health and safety with the beginning of the EEC in 1957. The main interest of the EEC was the safety and health protection of employees during work. The risks to employees' health resulted from their jobs, and therefore the legislation and the policies mainly addressed the topic from a protective perspective. This has changed in the context of prevention strategies. Therefore, the European Commission encourages member states to use the European Structural and Investment Fund (ESIF) to finance measures related to occupational safety and health $(\mathrm{OSH})$. It is addressed at employees, enterprises and entrepreneurs to implement new ways of work organization, education, increased productivity and training for better health and safety. To support health and safety issues, $\mathrm{OSH}$ also addresses mental well-being at work, social services and raising awareness among labour inspectors (European Commission, 2014). Although the EU has taken steps to incentivize employers to establish prevention measures to improve the health of their employees, the current situation in the EU is very different across the member states. The topic of health promotion is not part of the legislation of many member states and, in those countries where it is, implementation is mostly non-binding (Verra et al., 2019). Following the argumentation of (Verra et al., 2019), health promotion policies are infrequent and even more infrequently implemented, although the implementation of these policies is costefficient and generates profits and increases public health. (Verra et al., 2019).

Due to the large differences in policies among the member states of the European Union (Verra et al., 2019) and the lack of an option to generate legally binding policies, 
implementation on a national level seems preferable. Since IWHM leads to benefits for all affected parties, there would seem to be a market failure. A market failure is, according to Bator (1958) the incidence which causes the allocation mechanism to fail by not being able to maximize the welfare function. Although an alternative and, for all parties, the better allocation is possible, the allocation mechanism is incapable of providing the Paretoefficient optima. In the case of IWHM, all stakeholders could benefit from implementation defining the recent situation as a Pareto-inefficient level. However, the willingness to implement IWMH is limited due to several constraints such as incomplete information, which is mainly addressed by this paper, but also other factors such as resistance to change and inertia. Consequently, the implementation progress is taking longer than necessary to reach a Pareto-efficient optimum. Hence, a mandatory workplace health management system seems plausible and Pareto-efficient.

Although the studies presented clearly indicate a cost efficiency, implementation of the measures undoubtedly depends on a company's size. Small companies would face different issues, in terms of additional labour, compared to multinational corporations. Nevertheless, depending on the size of the company, certain legally binding policies for employers could be financially beneficial to all stakeholders. Since the practice of such an intervention is not very common and could increase resistance among the stakeholders, certain aspects could be adopted gradually. We, therefore, provide an example of the implementation of IWHM through an opting-in model from a German health insurer, which will be used as a blueprint for possible implementation.

The "Vereinigte Innungskrankenkassen" is a union of German health insurers. In 2016 they started to offer companies a reduction of $€ 100$ in their insurance contribution for each employee if they chose to produce a corporate health report. The health report was only necessary for companies with more than 30 employees to protect personal data, though small enterprises still had the opportunity to participate. The employers had to conduct yearly questionnaires to collect health-related information, and they had to implement two out of five possible measures. These measures were: establishing regular discussion sessions between employees of all levels concerning goals and leadership behaviour, an employee suggestion system, health circles, quality circles or regular staff interviews. The mandatory implementation of these two measures could be a gentle introduction to creating a workplace health management system. The insurer was willing to offer $€ 100$ for prevention measures that would decrease future medical treatment costs. Hence, in the case of mandatory implementation of an IWHM system, the insurers can later decrease the insurance premiums. The precise characteristics of the insurers IWHM offer can be found in the Appendix, Table 2.

German insurers invest 150 million euros per year in prevention measures for health care, which equates to $€ 2.19$ per person. Since the IWHM programs are also predominantly health preventive, mandatory implementation could increase the savings and public health benefits significantly. This mandatory approach would imply an increase of more than 20 times the amount of money invested in prevention but also lead to a saving of at least double the investment, taking the lowest return-on-investment rate. Henceforth, policymakers should consider mandatory workplace health management systems by simultaneously informing the employers of the benefits. The main reason for the 
implementation is the market failure which allows a new policy to constitute a Pareto improvement in comparison to the current market situation. This implies monetary savings for the employers and insurance companies, no negative monetary effects for the employees and an improvement in public health. Therefore, mandatory implementation of IWHM is not very likely to harm the competitiveness of European employers but rather to increase it.

\section{Conclusions}

This paper discusses the implications and effects of workplace health management systems and argues that workplace health management systems should be mandatory for employers. By using the concept of the German BGM, a Pareto improvement can be accomplished. The concept increases the health of employees, reduces the costs for insurers and increases the profits for employers. Since there is not enough evidence in studies based on the BGM concept, the current paper evaluates international studies on workplace health programs and studies about US "workplace wellness programs" to investigate the efficiency of integrated workplace health management systems such as the BGM. Based on this evaluation, the results indicate a market failure, since the costefficiency of the IWHM programs is proven, and a Pareto improvement can be achieved. This does not only apply to a few industrial sectors. It can be applied to a rather wide range of industrial sectors such as hospitality, tourism, energy communication, grocery retail, software, education, finance, manufacturing, and health care. Consequentially, it can be assumed to be generally applicable. Although the IWHM programs are very profitable for the employers, only a few companies use these programs. Yet, the health level of the employees can be improved; the insurance companies benefit from a decrease in expenses for medicine and medical treatment and the employer benefits from reduced costs for employee absence and the resulting productivity losses. A policy which forces employers to implement a minimal IWHM program could, therefore, be beneficial for all three stakeholders and lead to a significant improvement in public health, an increase in companies' competitiveness and savings for the public health insurance companies.

\section{References}

Baicker, K., Cutler, D., \& Song, Z. (2010). Workplace wellness programs can generate savings. Health Affairs (Project Hope), 29(2), 304-311. https://doi.org/10.1377/hlthaff.2009.0626

Berry, L. Mirabito \& Ann M. Baun, W. (2010). What's the Hard Return on Employee Wellness Programs? Harvard Business Review, December 2010; Mays Business School Research Paper No. 2012-68. Retrieved from https://ssrn.com/abstract=2064874.

Buchenau, P. (Ed.). (2018). Chefsache Gesundheit. I: Der Führungsratgeber fürs 21. Jahrhundert/ Herausgeber Peter Buchenau (2. Auflage). Wiesbaden: Springer Gabler.

Bulotaitè, L., Šorytè, D., Vičaitè, S., Šidagytè, R., Lakiša, S., Vanadziṇš, I., . . . Lerssi-Uskelin, J. (2017). Workplace health promotion in health care settings in Finland, Latvia, and Lithuania. Medicina (Kaunas, Lithuania), 53(5), 348-356. https://doi.org/10.1016/j.medici.2017.10.002

Cullen, K. L., Irvin, E., Collie, A., Clay, F., Gensby, U., Jennings, P. A., . . A Amick, B. C. (2018). Effectiveness of Workplace Interventions in Return-to-Work for Musculoskeletal, Pain-Related and Mental Health Conditions: An Update of the Evidence and Messages for Practitioners. Journal of Occupational Rehabilitation, 28(1), 1-15. https://doi.org/10.1007/s10926-016-9690-x 
European Commission (2014). Communication from the Commission to the European Parliament, the Council, the European Economic and Social Committee and the Committee of the Regions on an EU strategic framework on health and safety at work 2014-2020. European Commission, Brussels.

Hoffmann, M. (2019). Mitarbeiterbindung: Welche Anreize für Arbeitnehmer am wichtigsten sind Manager Magazin. Retrieved from https://www.managermagazin.de/unternehmen/karriere/mitarbeiterbindung-welche-anreize-fuer-arbeitnehmer-amwichtigsten-sind-a-1186892.html

Huber S. (2010). Betriebliches Gesundheitsmanagement und Personalmanagement. In: Esslinger A.S., Emmert M., Schöffski O. (eds) Betriebliches Gesundheitsmanagement. Gabler.

Junker N. M., Kaluza A. J. (2018). Möglichkeiten und Grenzen im digitalen BGM aus Unternehmenssicht. In: Matusiewicz D., Kaiser L. (eds) Digitales Betriebliches Gesundheitsmanagement. FOM-Edition (FOM Hochschule für Oekonomie \& Management). Springer Gabler, Wiesbaden

Kern, A. O. (2018). Betriebliches Gesundheitsmanagement ist Führungsaufgabe und Erfolgsfaktor. In P. Buchenau (Ed.), Chefsache Gesundheit. I: Der Führungsratgeber fürs 21. Jahrhundert/ Herausgeber Peter Buchenau (2nd ed., pp. 157-174). Wiesbaden: Springer Gabler. https://doi.org/10.1007/978-3-658-16580-2_9.

Kruse, O. \& Wittberg, V. (2016). Fallstudien zur Unternehmensführung. Wiesbaden: Gabler Verlag.M. Young, The Technical Writer's Handbook. Mill Valley, CA: University Science.

Marschall, J., Hildebrandt, S., Zich, K., Tisch, T., Sörensen, J., Nolting \& H. D. (2018). DAKGesundheitsreport 2018. DAK. Retrieved from www.dak.de/dak/download/gesundheitsreport2018-1970840.pdf.

Ryan, T., Rice, V., Saunders, J., \& Limbrick, S. (2018). Measuring the effectiveness of workplace health management programs: An Australian example. Preventive Medicine Reports, 11, 5662. https://doi.org/10.1016/j.pmedr.2018.04.018.

Scholz A., Singh U., Ghadiri A., Peters T. (2018). Nachhaltiges betriebliches Gesundheitsmanagement - Empfehlungen für die Implementierung in der Praxis. In: Gadatsch A., Ihne H., Monhemius J., Schreiber D. (eds) Nachhaltiges Wirtschaften im digitalen Zeitalter. Springer Gabler, Wiesbaden.

Singer S., Neumann A. (2010). Beweggründe für ein Betriebliches Gesundheitsmanagement und seine Integration. In: Esslinger A.S., Emmert M., Schöffski O. (eds) Betriebliches Gesundheitsmanagement. Gabler.

Thiehoff, R. (1999). Rechnet sich Arbeitsschutz im Betrieb? Arbeitsschutz und Wirtschaftlichkeit. Hg. v. R. Thiehoff. Bundesanstalt für Arbeitsschutz und Arbeitsmedizin. Dortmund (BKKGesundheitsreporte 2003-2010.).

Verra, S. E., Benzerga, A., Jiao, B., \& Ruggeri, K. (2019). Health Promotion at Work: A Comparison of Policy and Practice Across Europe. Safety and Health at Work, 10(1), 21-29. https://doi.org/10.1016/j.shaw.2018.07.003.

The research paper has been reviewed. | Received: March 25, 2019; Revised: April 23, 2019; Accepted: April 25, 2019; Prepublished online: April 27, 2019; Published: April 28, 2019 


\section{Stage 1:}

A bonus of up to $€ 100$ for the company and each employee insured with the IKK will be paid if these three measures are implemented.

1. Your company prepares a yearly health report with our participation if your company has more than 30 employees. Otherwise a general industry report is sufficient.

2. Your company uses a questionnaire once a year to collect data about health-related issues from your employees

3. Your company systematically analyses health-related information which was collected through other internal processes. This can be accomplished by using at least 2 of the following options:
a) health circles
b) quality circles or similar improvement processes
c) one-to-one employee meetings
d) leadership and target-setting meetings
e) employee suggestion program

\section{Stage 2:}

A bonus of up to half the monthly insurance contribution for the company and each employee insured with the IKK will be paid if, in addition to the measures of stage 1, the following measures are applied:

1. Your company offers internal health-promotion measures which directly affect the health and well-being of the employees. At least 4 of the following points have to be implemented, and at least 10 per cent of the workforce have to participate regularly.

- providing gyms and rest areas

- granting additional paid short breaks

- effective non-smoker protection

- enabling IKK employees to have IKK check-ups during worktime

- supporting company sports activities

- offering health-related sports activities

- offers for stress reduction

- offers for healthy nutrition

- training managers in staff-oriented leadership

- internal offers for addiction prevention

- offers for specific groups (e.g. older employees, trainees, mothers)

2. All employees have the opportunity to actively engage in health-related questions and participate in changes

3. All employees are appropriately informed by internal communication about the goals of the company's specific health-promoting services.

\section{Stage 3:}

A bonus of up to one month's insurance contribution for the company and each employee insured with the IKK will be paid if, as a result of applying the measures in stage 1 and stage 2, the following results have been achieved:
a) reduction in sickness rates
b) reduction in expenditure on pharmaceuticals
c) reduction in expenses for hospital stays

Cost savings due to law/policy changes and dismissals are not considered. The information (average and age-related costs) from the two previous years will be used to determine whether the criteria have been met. Evaluation of points (a-c) will be conducted by the IKK and made available to your company. Please, therefore, contact the IKK in good time.

Source: Kruse \& Wittberg (2008). 